\title{
Adsorbed water clusters in garnet cracks detected by impedance and Raman spectroscopies at the supercooled water phase transition
}

\author{
Pedro Prezas ${ }^{1}$, Hugo Gonçalves Silva ${ }^{2}$, Ana Vinagre ${ }^{3}$, Manuel Pedro F. Graça ${ }^{4}$, Patrícia Moita ${ }^{3}$, \\ and Mourad Bezzeghoud ${ }^{2}$
}

\begin{abstract}
The combination of electric impedance and Raman spectroscopies at the analysis of the supercooled water phase transition enables the detection of adsorbed water clusters in garnet minerals of leucogranite samples. This transition is revealed by a change in the parameters measured by both techniques at low temperatures, $T_{c} \sim 220 \mathrm{~K}$, and it is attributed to adsorbed water clusters in the walls of garnet cracks. The study of this transition gives important insights into the water-rock interaction, one of the most important points in the study of rock alteration. The dielectric spectra were fitted to the Havriliak-Negami model of dielectric relaxation and enabled the estimation of the activation energy of the dielectric relaxation process as $E_{a} \sim 76 \pm 3 \mathrm{~kJ} \mathrm{~mol}^{-1}$, which is higher than the energy attributed to water molecule
\end{abstract}

reorientation in bulk ice. We determined that this energy should be related with the interaction forces between the adsorbed water clusters and the crack walls that hinder the reorientation of those molecules. The logarithmic frequency dependence of the critical transition temperature was also verified. Raman spectra allowed the identification of the water cluster vibration band, $\sim 3680 \mathrm{~cm}^{-1}$, in the garnet minerals. The band disappears for temperatures around $423 \mathrm{~K}$ where the joint action of the laser beam and the temperature evaporates the adsorbed water clusters. This excludes the possibility that the observed supercooled phase transition could be related with structural water in chlorite minerals. The samples had low apparent porosity $\sim 1.29 \%$, specific surface area, and adsorption average crack width (using the BrunauerEmmett-Teller method) of $\sim 0.18 \mathrm{~m}^{2} \mathrm{~g}^{-1}$ and $\sim 7.92 \mathrm{~nm}$, respectively.

\section{INTRODUCTION}

Dielectric relaxations, associated with water in rock pores, have been the focus of intense research due to their importance in geoelectric borehole logs for petroleum prospection (Chelidze and Guéguen, 1999; Chelidze et al., 1999). Different types of rocks, various concentrations of water, and diverse dissolved salts were studied to clarify the water-rock interaction (Knight and Abad, 1995), which is a highly complex process that it is crucial to understand geoelectric borehole logs. At low water concentrations, a thin layer of water coats the rock pores forming an electric double layer (Revil, 2013). The electric charges within this layer compensate the electric charges existing on the surface of minerals, resulting in a $\alpha$ polarization (Revil, 2013), which is responsible for the dielectric relaxation of water at room temperatures.

Because less attention has been given to low-temperature dependence of the dielectric relaxations, linked with adsorbed water in rocks, and it is important because temperature-dependent dielectric spectroscopy gives key insights in the relaxation kinetics by the estimation of its characteristic activation energies, it is essential to do research in this area. This technique is widely used on material characterization (Graça et al., 2008), but few studies are done on rocks (Silva et al., 2014). Moreover, other dielectric relaxations developed at low temperatures that are of interest for fundamental and

Manuscript received by the Editor 4 October 2014; revised manuscript received 4 March 2015; published online 26 May 2015.

${ }^{1}$ Formerly Universidade de Évora, Departamento de Física, ECT, Instituto de Ciências da Terra, IIFA, Évora, Portugal; presently University of Aveiro, I3NPhysics Department, Aveiro, Portugal. E-mail: pedro.rafael@ua.pt.

¿ Universidade de Évora, Departamento de Física, ECT, Instituto de Ciências da Terra, Évora, Portugal. E-mail: hgsilva@uevora.pt; mourad@uevora.pt.

${ }^{3}$ Universidade de Évora, Hercules Laboratory, Évora, Portugal; and Universidade de Évora, Departamento de Geologia, Évora, Portugal. E-mail: ana vinagre @ gmail.com; pmoita@ uevora.pt.

${ }^{4}$ University of Aveiro, I3N-Physics Department, Aveiro, Portugal. E-mail: mpfg@ua.pt.

(C) 2015 Society of Exploration Geophysicists. All rights reserved. 